\title{
Opportunity-driven IT service management
}

\section{Cameron Fisher}

provides IT Service Management consulting to large organizations. His current project addresses IT service planning for a client with over 150,000 devices and global users. He holds an M.S. degree in Technology Management from the University of Pennsylvania School of Engineering and The Wharton School, as well as an M.B.A. degree from New York University.

Keywords: ITIL, IT service management, CRM, service pipeline, service catalogue, asset management

Abstract Information Technology (IT) service management is increasingly opportunitydriven. IT Infrastructure Library (ITIL) version 3 and the Service Portfolio apply service lifecycle and portfolio management techniques. Business service development and service innovation is a vital path to the future. Marketing techniques are relevant and applicable to IT professionals. Such techniques include: service catalogue, professional services automation, project portfolio management, customer relationship management, service pipeline and the task marketplace.

Journal of Digital Asset Management (2008) 4, 377-394. doi:10.1057/dam.2008.41

Information Technology (IT) managers wear many hats to administer IT operations. How did applying marketing principles and seizing opportunities across the service lifecycle become essential?

Sure, we hear a lot about IT professionals needing to acquire more business skills. But relatively few people with a deep IT background are also experts at marketing. This may be due to background, mindset, comfort level or simply specialization due to limits on human bandwidth.

Marketing is a fluffy and creative activity better left to marketers. Marketing principles and techniques are certainly outside the core mandate of IT professionals. Or are they?

Historically, IT professionals prefer to:

- limit expectations;

- avoid over-promising;

- control scope creep;

- refrain from premature celebrations that could bite back later.

Contractual and Statement of Work targets are difficult enough already. So why bother striving to offer more than the minimum necessary to sustain IT operations?

We have seen some hardware become increasingly commoditized. Web and application platforms are also increasingly commoditized, out-sourced or offshored. With open architecture, unified standards and common data models, IT professionals are arguably becoming less about technology and more about innovation, business development and go-tomarket initiatives.

If the "buy versus build" decision increasingly shifts to "buy", then what roles are left for IT professionals to perform to continue to be invaluable to the organization? The answer exists upstream in the value chain: business services manager, pipeline manager, relationship manager and transformation agent.

Increasingly, IT professionals are expected to cater to business requirements and understand the scorecards, metrics and tools of business such as budgets, P\&L, forecasting, cash flow, ROI, process modeling, etc.

In response, many feel the need for continual transformation. An "adapt or be out-sourced" mantra is more widespread with the growing reliance on lower-cost out-sourcers based in India, Russia, China, Singapore and elsewhere. Employees with traditionally secure roles can feel vulnerable to down-sizing, demotion and layoff.

\section{MARKET PRESSURES}

Important trends are changing the way we think about IT responsibilities and internal marketing. 
A cultural shift is underway and IT professionals need to adapt.

Moreover, business managers are increasingly IT savvy. A recent InformationWeek CIO Effectiveness study of senior professionals found that 46 per cent of business managers are taking on more responsibility for IT projects compared to the prior year (Figure 1).

It may be true that IT savvy business managers will collaborate better and improve cross-enterprise communication.

Correspondingly, IT professionals need to become more business savvy to maintain their credibility and influence.

In view of the complexities and interdependencies across IT, an understandable aversion has evolved against scope creep, over-promising and missed budget/timeline targets.

When project aspirations and contract milestones are already difficult to attain, IT professionals historically were reluctant to strive to offer more than the minimum thresholds of existing service-level agreements (SLAs).

Nevertheless, these dis-incentives and cultural inhibitors need to be overcome to achieve improvements in:

- customer satisfaction;

- customer loyalty/retention;

- worker morale and human capital development;

- innovativeness.

Typically, IT professionals focus on operations and efficiency. So we ask, "Do they really need to profile and segment their users and be prepared to pitch follow-on services?"Y Yes, IT needs to consistently demonstrate value-add and communicate these successes to guard against losing demand for their services.

This paper's purpose is to point out trends and shifts in IT professionals as innovators with marketing and service/product responsibilities. This paper will also:

- review important factors in the service provisioning eco-system;

- outline new techniques and developments that are now available;

- recommend specific improvements and tools for short-term and intermediate-term gains.
Business Managers Taking More IT Responsibility?

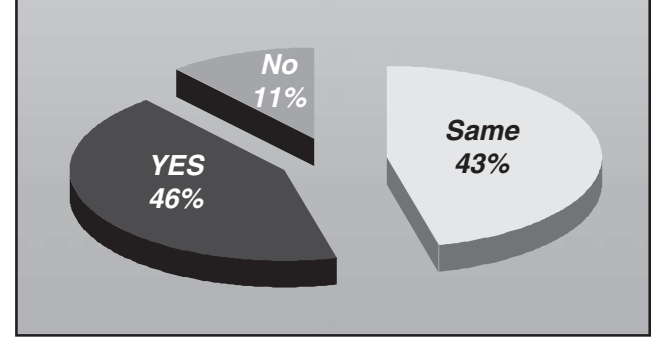

Figure 1: Forty-six per cent of business managers surveyed plan to take more IT responsibility

\section{IT PROFESSIONALS AND THEIR MARKETING CHALLENGES}

In the past, Tom Seibel and other customer relationship management (CRM) leaders provided techniques for building customer intimacy that enabled performance gains for customer-centric offerings that delight customers. Today, IT professionals are being assessed by a similar lens.

When users contact an internal help desk for simple or complex requests, their customer experiences, satisfaction metrics and low-cost sourcing are being compared to those of worldclass service centers available, such as Sears or Visa.

IT professionals may refer to their constituents as "users". But these users are increasingly less captive. Users need to be recognized and treated as customers who have many choices and options in their suppliers.

For example, customers today can subscribe to application service providers that host the servers, perform upgrades and pledge high availability. Many organizations choose to focus on their core strengths, and purchase blanket out-sourcing contracts to gain reliability, expertise, efficiencies and to reduce distractions from core competencies.

SaaS (Software as a Service) and utility computing are gaining proponents. IT professionals increasingly need to demonstrate business value and flexibility in order to retain influence over IT and business operations. Unless value-add opportunities are seized, IT managers might resign themselves to being viewed as procurement managers. 
Some IT managers have difficulty effectively explaining, negotiating and promoting their IT services in a way that their customers can relate to and respond to in view of customers' knowledge, needs and hot buttons. Going forward, this difficulty needs to be overcome. The recommendations below outline methods for IT professionals to better communicate, promote and market IT offerings to their key stakeholders.

\section{ESTABLISHED AND NEW TECHNIQUES COME TOGETHER}

New innovations are now possible as established and new techniques converge. CRM and professional services automation (PSA)

originated several years ago.

The gains provided by ERP in a manufacturing factory setting are similar to the gains provided by systems management in an information factory. Exciting improvements in systems management (including service desk, release management, configuration management, etc) are combining with advances such as IT Infrastructure Library (ITIL) and PPM (project portfolio management) to opportunistically affect the way that tasks and projects are brokered and fulfilled in the IT marketplace.

In addition to design and support of various business systems, IT contributes input and uses multiple systems that affect new business development, new service offerings, CRM and opportunity management. Depending on the situation and the actors involved, the touchpoints can be direct or indirect (Figure 2).

An IT service desk does not compete with an existing CRM system per se, because the CRM tends to look at external, revenuegenerating customers. However, what characterizes a customer or a provider can vary at different times, or in different situations. The boundaries of business versus IT stakeholders are more fluid.

In CRM, an opportunity is typically matched to a contact, organization and product catalogue and then managed through the pipeline. The selling opportunity lifecycle has stages such as

- identify lead;

- qualify;

- contact;

- prospect;

- needs analysis;

- presentation;

- proposal;

- negotiate;

- close/contract/fulfill;

- extend.

Indeed, tools such as BMC Remedy ARS and Atrium are used successfully in both outwardfacing CRM or as inward-facing service desk solutions. Increasingly such IT solutions span and overlap customer service, CRM, supply management, service desk, systems management

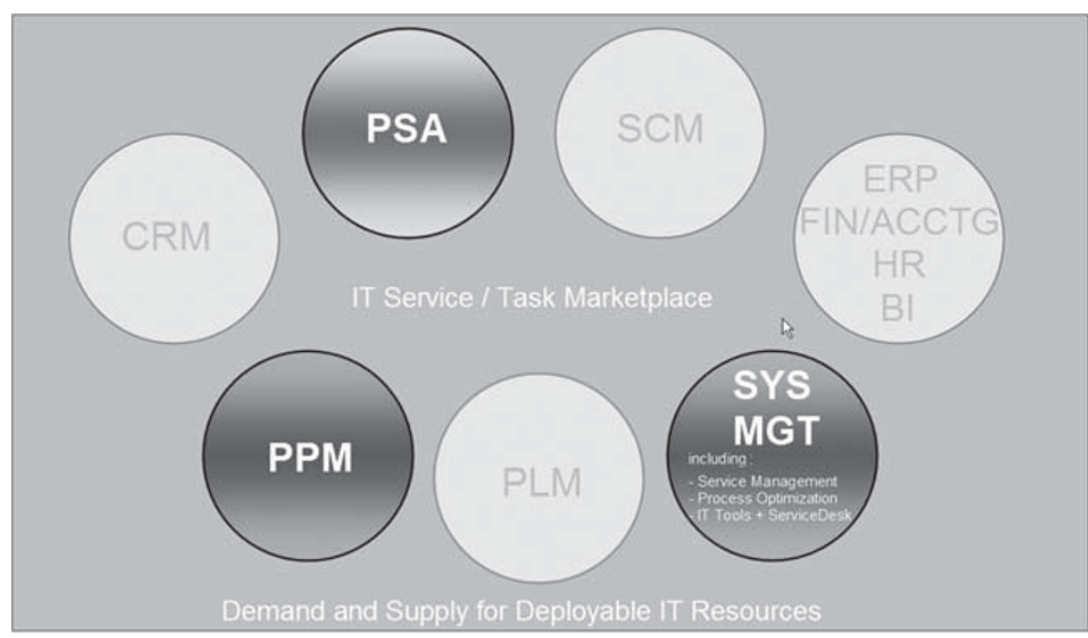

Figure 2: IT touchpoints for innovation and opportunity management 
and PPM. Project Portfolio management includes managing projects, new application development initiatives or updating core business systems.

\section{Service portfolio}

During the 1970s, the Boston Consulting Group established principles of portfolio management for managing growth of stars, cash cows and dogs. Similarly, CA Clarity and IBM Tivoli offer examples of PPM used for IT project planning as well as product lifecycle management (PLM, sometimes known as pipeline management).

Increasingly, IT professionals are building a service portfolio comprised of service pipeline and service catalogue to manage risks and costs. Is this catalogue comparable to a Sears merchandising catalogue? Yes, in some respects.

IT management typically will configure and bundle offerings, and understand the amounts of labor/hardware/network ingredients required. Armed with cost, competitor and company information, IT can better manage pricing, margins, inventories and demand during peaks and valleys, and replacement cycles.

With a well-defined catalogue of standard IT capabilities established, agreements regarding level of service are possible. These SLAs define terms and conditions for how business needs are satisfied by IT. A business manager will usually seek to attain no greater caliber of service than needed, at lowest reasonable price.
Figure 3 shows the evolved approach that exhibits similarities to PLM, CRM pipeline management, product portfolio management and project portfolio management (PPM).

In service product development, the innovation pipeline manages opportunities through stages that include exploration, plan, design, transition, operation and retirement. The pipeline illustrates stages such as market space, concept, analysis, approval and charter, for which an innovative new service concept can progress. Influenced by overall business strategy, market research and customer input, new services or changes are formally conceptualized and managed.

As new service offerings are formulated and analyzed, the concept progresses through the service pipeline for approval, rejection or re-work. As the status of a new service idea matures through the portfolio from design to transition to operation (and ultimately retirement), appropriate resources are engaged and released.

Figure 4 depicts how, once chartered, offerings progress from pipeline into catalogue. The offerings become visible to customers in the service catalogue.

A catalogue of IT services is a useful vehicle for achieving standardization, consistency, cost transparency and SLA. Some firms may lack well-developed transfer pricing, charge back or activity-based costing methods. Service processes

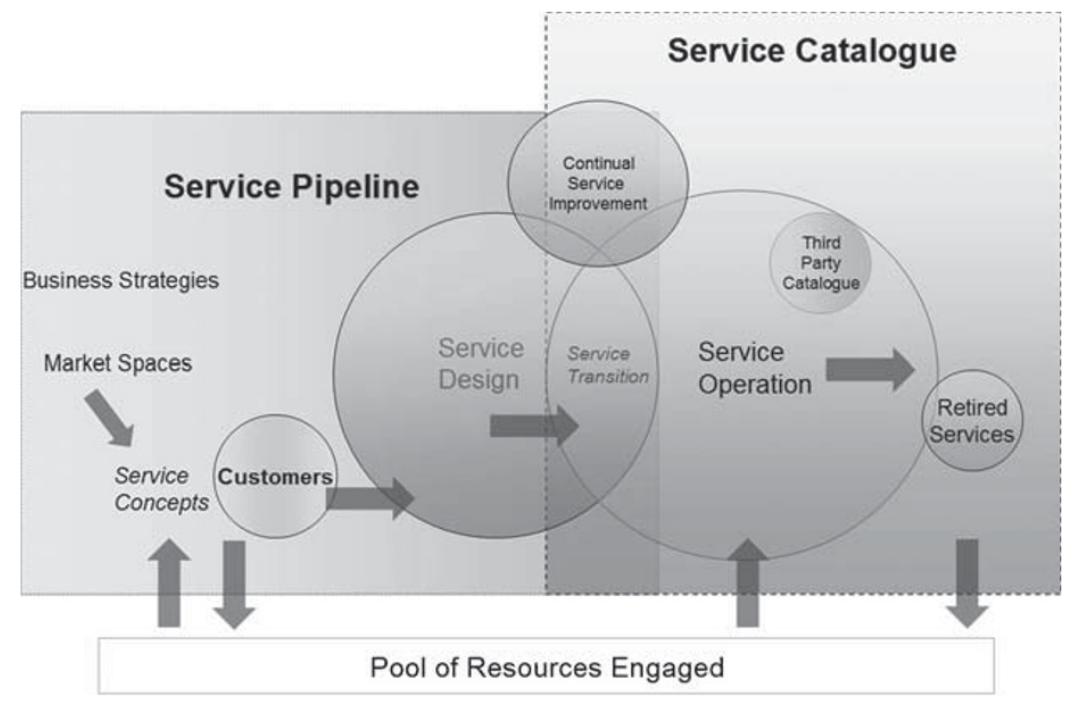

Figure 3: Service portfolio 


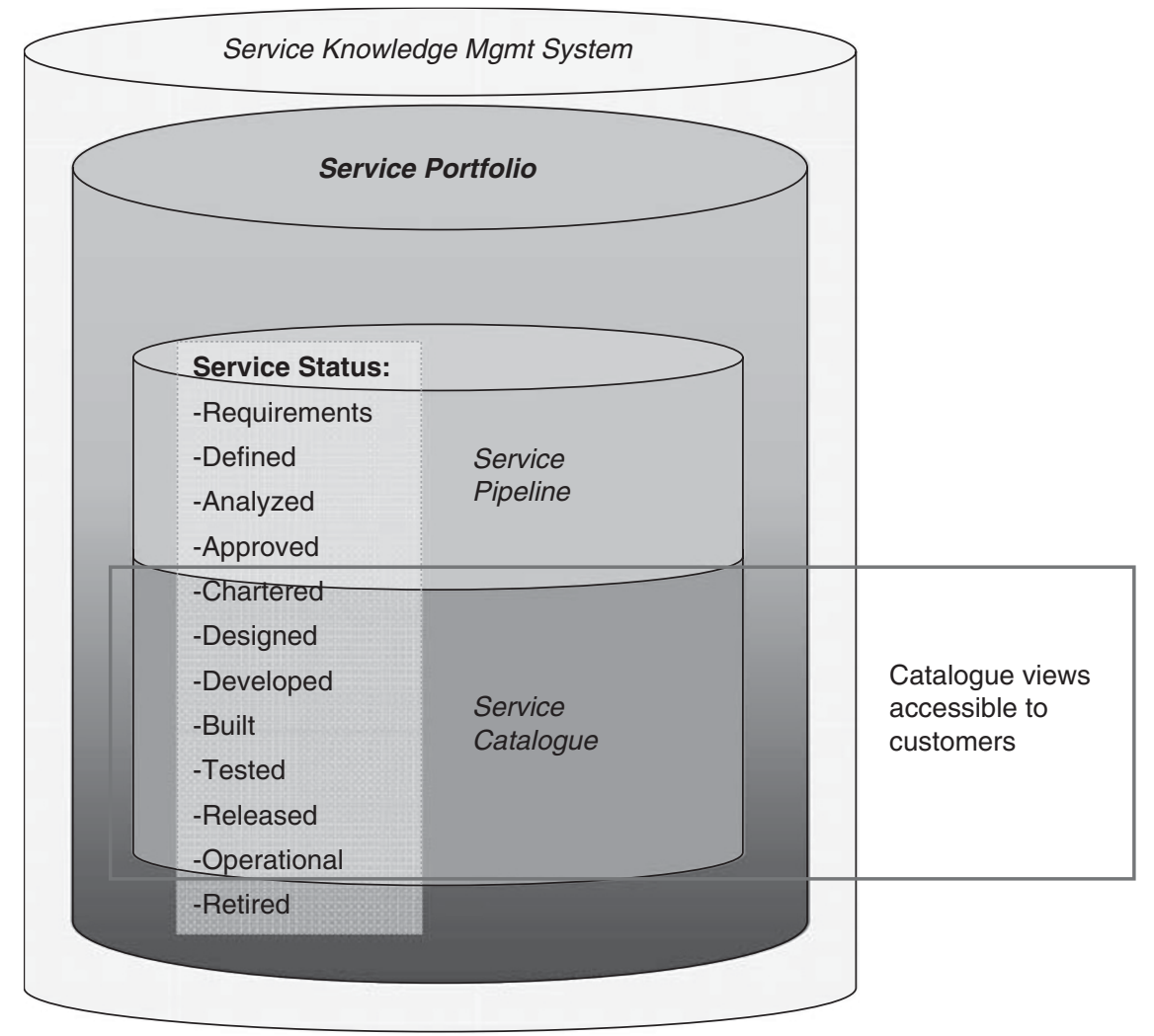

Figure 4: Service pipeline and service catalogue

will usually involve terms such as project, vendor, problem, provision, change, consult, capacity, etc. A service is more than just a technical component view. Examples of a service include on-boarding a new employee, hosting a new application or provisioning a new server.

Suppose IT offers desktop provisioning when on-boarding new employees. The requesting line-of-business approver does not care to know about conforming to prescribed device standards, install applications, security and patches and gain network access. It is the service capability (not merely the components) that is needed when the new employee arrives to begin work.

In Figure 5, it is Services A, B, C, .., G, which are central to service-level management.

ITIL Version 3 provides a framework for process coordination and optimization. Service catalogue and service level management are central to a service lifecycle. This lifecycle is explained in ITIL v3: Service Design — Book 2, Chapter 4.

A catalogue is an important foundation for showing what IT provides to the organization. The catalogue contributes by proactively displaying the offerings. An IT manager may report that "90 per cent of applications outages are restored within 7 minutes." But is that significant to the business managers' priorities? What was the dollar and business impact? How are service levels tracking and trending? Did the service fulfill a need and satisfy expectations? What adjustments or quality assurance measures need to be taken?

The catalogue enables better management of stakeholder expectations, communications and pricing mechanisms with definitions and terminology that customers can understand. Many of us agree that an important element of any customer-centric focus is for customers to easily know how to conduct business with the providing organization.

The important service elements captured by a service catalogue include:

- service name, description, identifier, key users, key support requirements;

- ownership, authority, accounting, change impact, service-level information; 


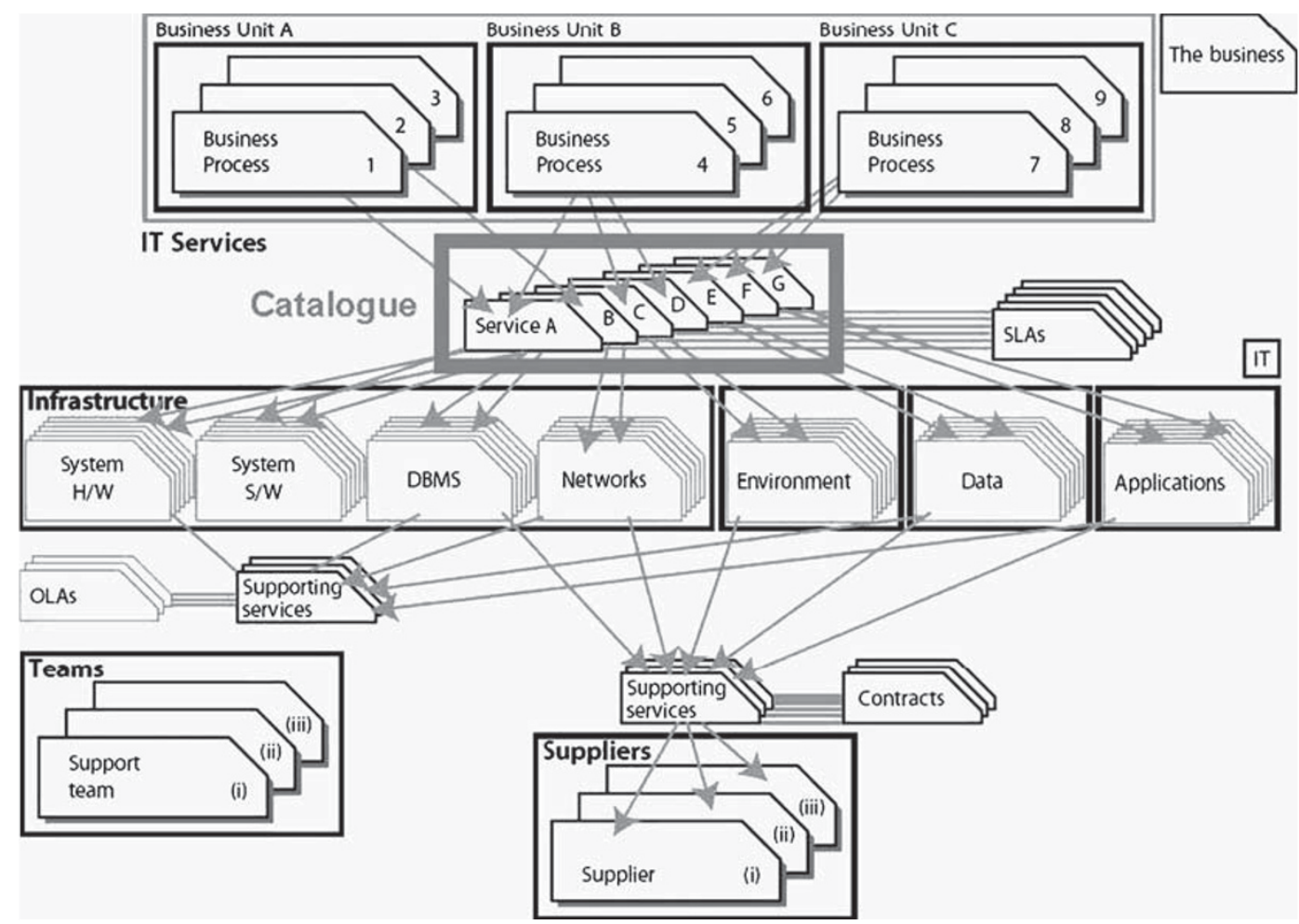

Figure 5: IT services, business processes and the role of service catalogue Source: ITIL version 3.

- customer expectations regarding performance, pricing, deliverables;

- resources for delivering business services to customers;

- requests and resources to align IT with business imperatives.

Table 1 provides an example of information managed within an organization's service catalogue.

In addition to the example above, the following attributes are also commonly found in a service catalogue containing details for each service offering:

- target audience;

- service pre-requisites;

- service restrictions;

- instructions for requesting service.

A service catalogue plays a critical role in communicating service offerings and in managing an organization's service management capabilities.
A detailed framework is provided by the OGC (UK-based Office of Government Commerce), which publishes the ITIL framework. With growing acceptance in the IT community, ITIL offers standardized vocabulary, process definition consistency and management standards within service management and across the service lifecycle.

Case example

A global investment bank experienced growth via acquisitions, but a patchwork of entities remained. Consolidation and integration was vital to coordination and cost efficiencies. A service catalogue can help reduce redundant business investments, duplicated efforts and rogue technologies

A well-managed shared services model will improve time-to-market of new financial offerings and enable re-use of application components. In this case, a "United Bank" theme communicated globally helped rally support for rationalization, process streamlining and inter-division consistency 


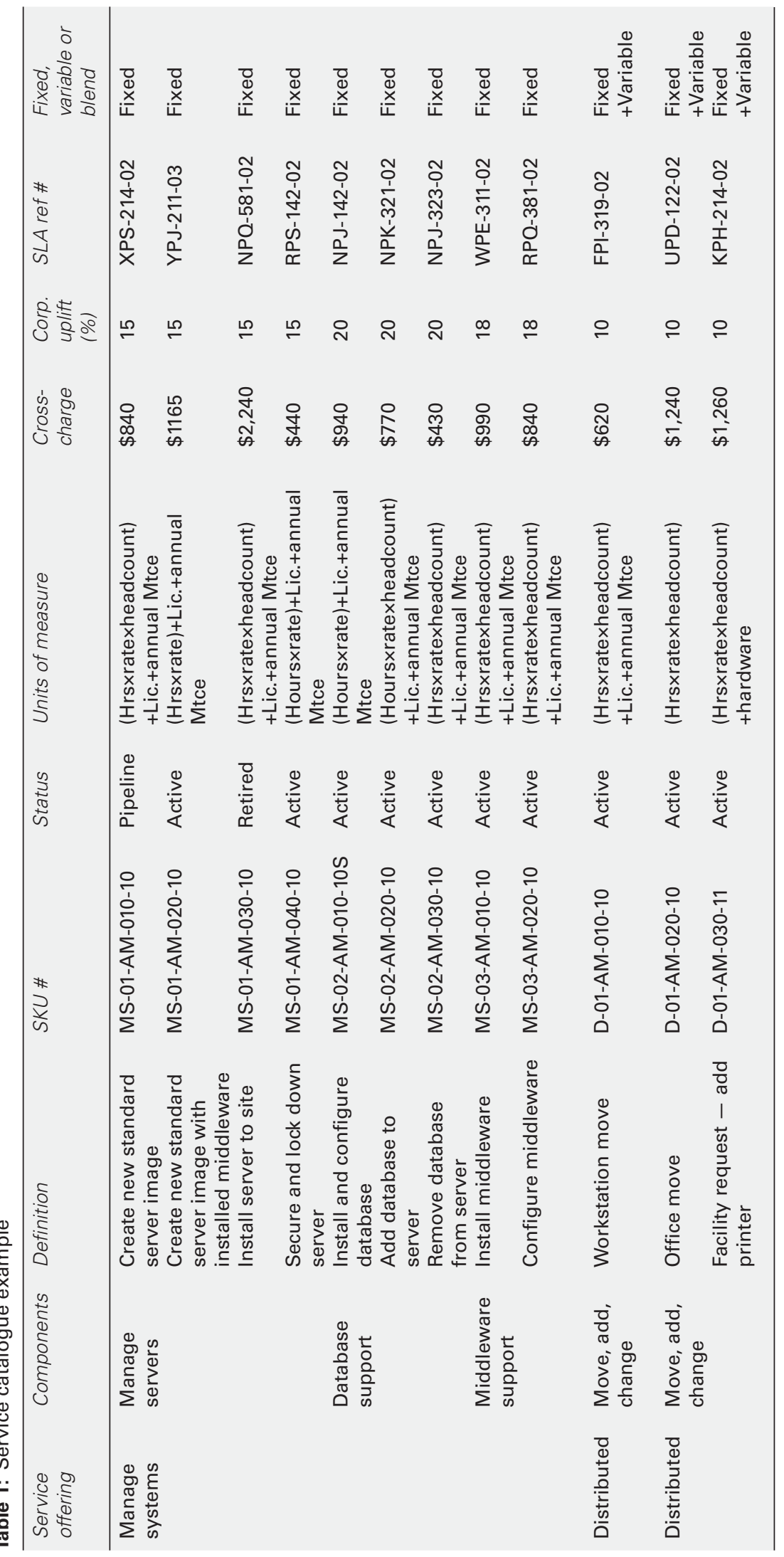




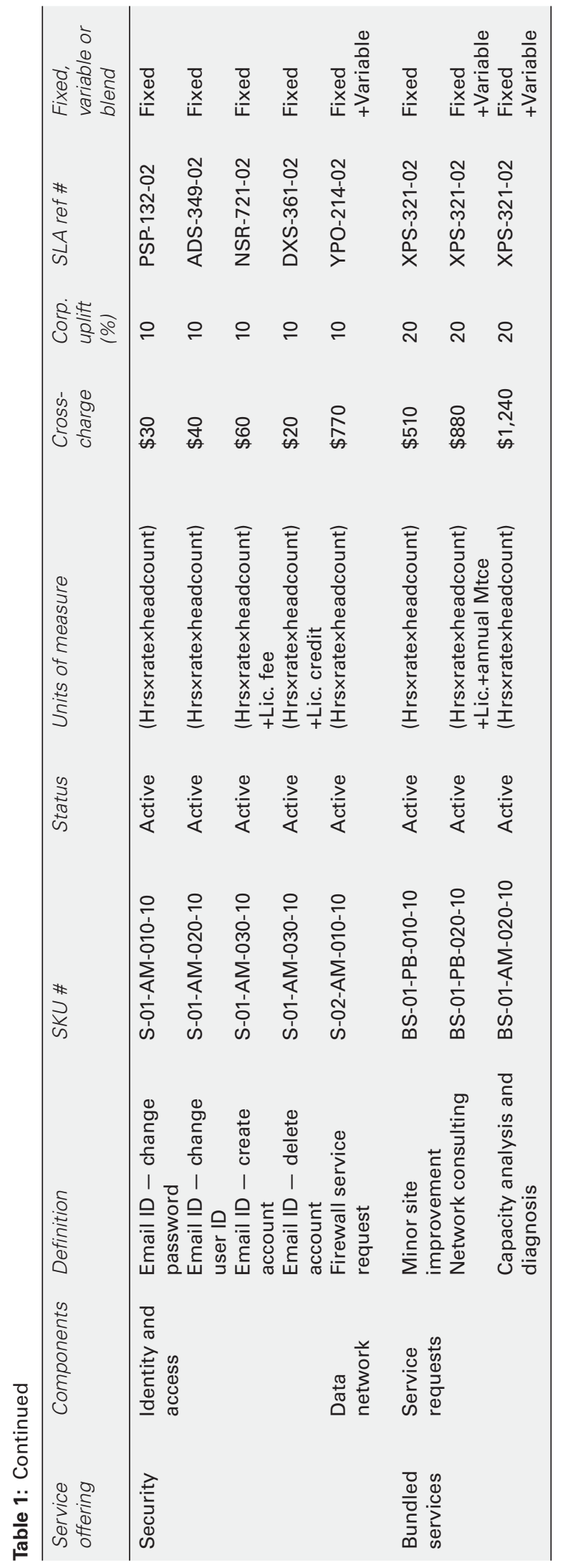




\section{Professional services automation}

During the late 1990s, PSA, in parallel to CRM, evolved as a better way for law firms, accounting firms, systems consultants and other service providers to offer, deliver and manage their accounts.

When such firms put a service capacity in place (like a seat on an airplane during a flight or a lawyer's time), the service resource is perishable. Once a plane takes off, any new passenger revenue opportunity is not realizable. Hence, professional service automation is motivated to better match resource availability, revenue opportunities and supply costs for professional service providers. In contrast to product-only offerings, a service catalogue offering often contains hardware, software, labor and postpurchase support and warranty elements. These elements comprise the "total solution."

While CRM and marketing management are opportunistic, IT management in contrast is traditionally constrained by obligations to reliability, availability, compliance, efficiency and security. But the ability to seize opportunities is still quite valuable to IT professionals.

Such solutions often contained a product catalogue and a pricing catalogue. Hence, service catalogues and PSA solutions are intertwined as important contributors to overall service management. Anyone acquainted with ERP software may wish to view PSA as an ERP system for a services organization. That is, integrated components for managing demand, supply, fulfillment and reporting.

How can IT professionals become more market driven and market aware? The service lifecycle can help by allowing for more of the customer-centric opportunity management, and still preserve a framework for segregation of duties, actor coordination and operational reliability.

With on-demand teaming, remote/virtual contributors (resources) and a plugged-in service center handling requests/incidents, what is increasingly constructed is a task marketplace or clearinghouse.

\section{Opportunity-driven IT service management}

The concept of "internal customers" and the recognized need for customer-centric services gained wide acceptance in recent years. Today, most employees understand the importance of
Table 2: Match resource need to pool of available candidate profiles

\begin{tabular}{l} 
Project name \\
Project start/end dates \\
Urgency \\
Project duration \\
Project location \\
Compensation rate/day and hierarchy level \\
Role sought \\
Skills required \\
Position details \\
Quantity of people \\
Languages needed \\
Primary skill emphasis \\
Secondary skill emphasis \\
Comments \\
Approved for government clearance \\
Technical certifications sought \\
Relevant discipline: University/College \\
Relevant discipline: technical certifications \\
Candidate profiles provided via application for \\
consideration \\
When available date \\
Base geographic location \\
Work history \\
Languages \\
Oredentials \\
Other requirements (wheelchair, Braille terminal, etc) \\
\hline
\end{tabular}

being responsive to internal or external customer needs. However, with the advent of virtual teams, just-in-time projects and skill sets that can atrophy or lose market value, a significant portion of current assignments are consumed by planning for the next assignment.

To avoid layoffs and ensure their skills stay current, the resource has one eye on customer fulfillment and the other eye on positioning themselves for the next assignment. Improving their personal market value as an employee is like building a personal brand. The worker seeks to build loyalty, repeat business and their reputation as a go-to person. The prevalence of internal and external job board postings enables projects of all types to post requirements to a clearinghouse where task, talent and price are established.

Fewer jobs in the workplace are static. Job descriptions themselves are less constrained and 


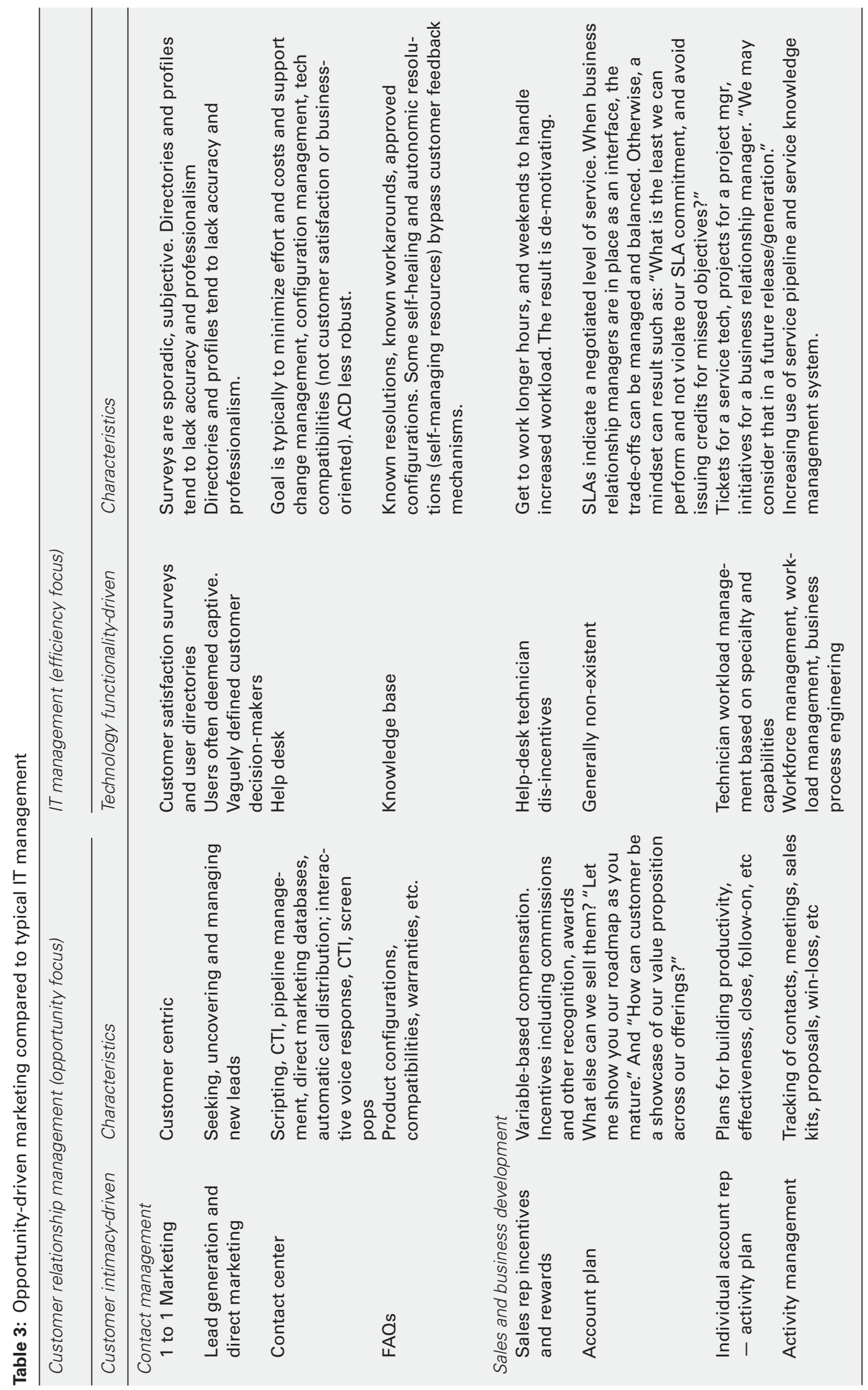




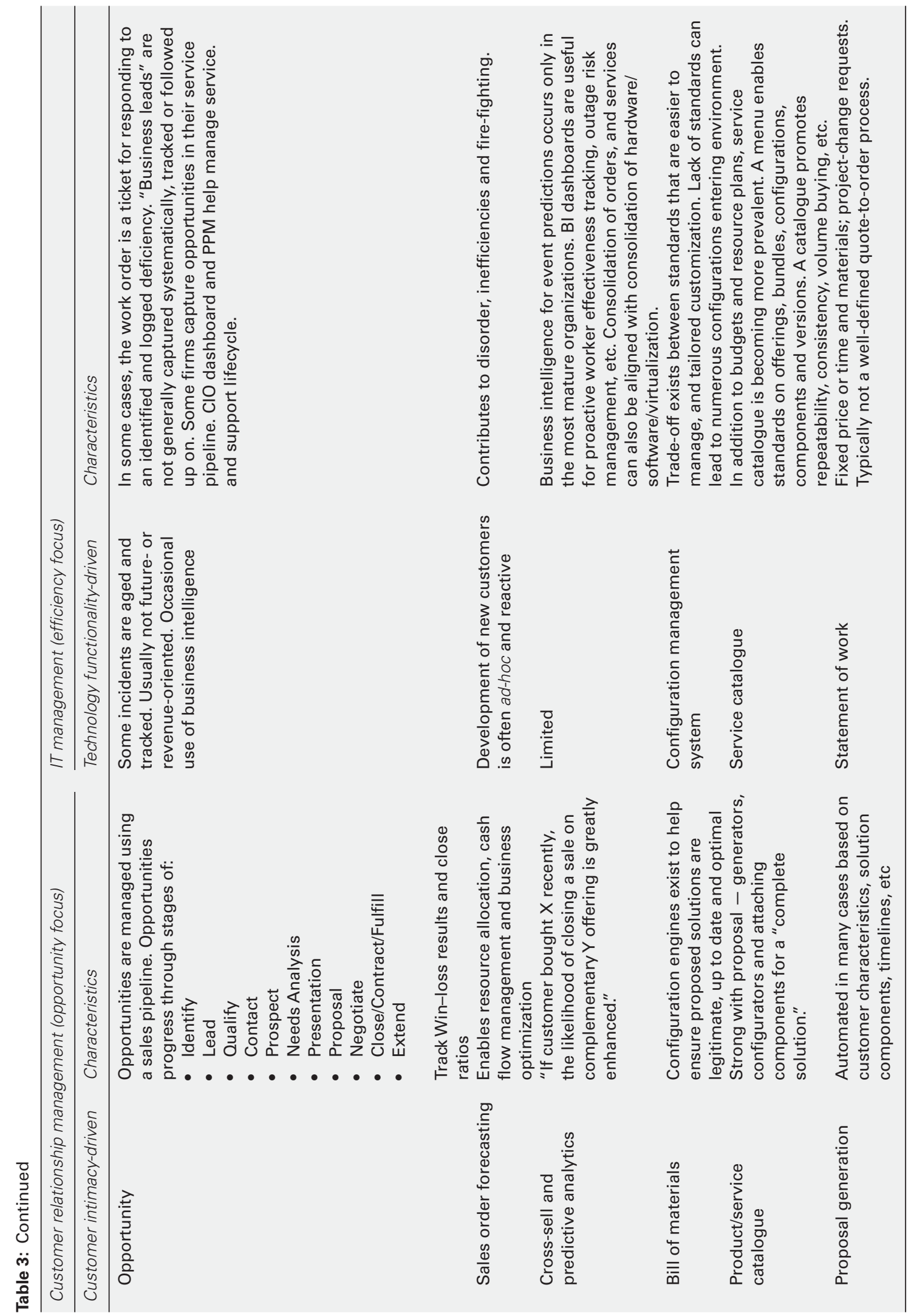




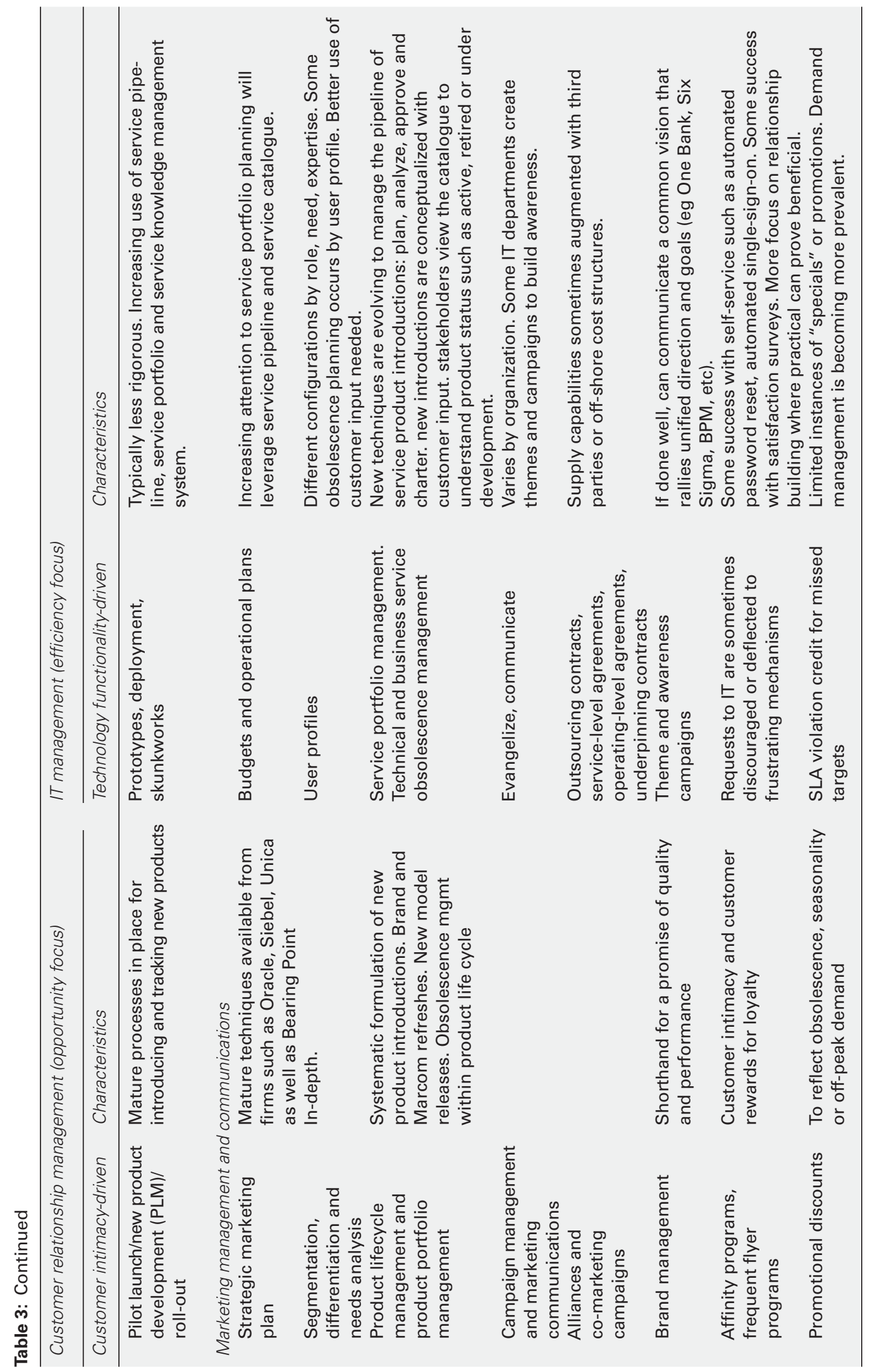




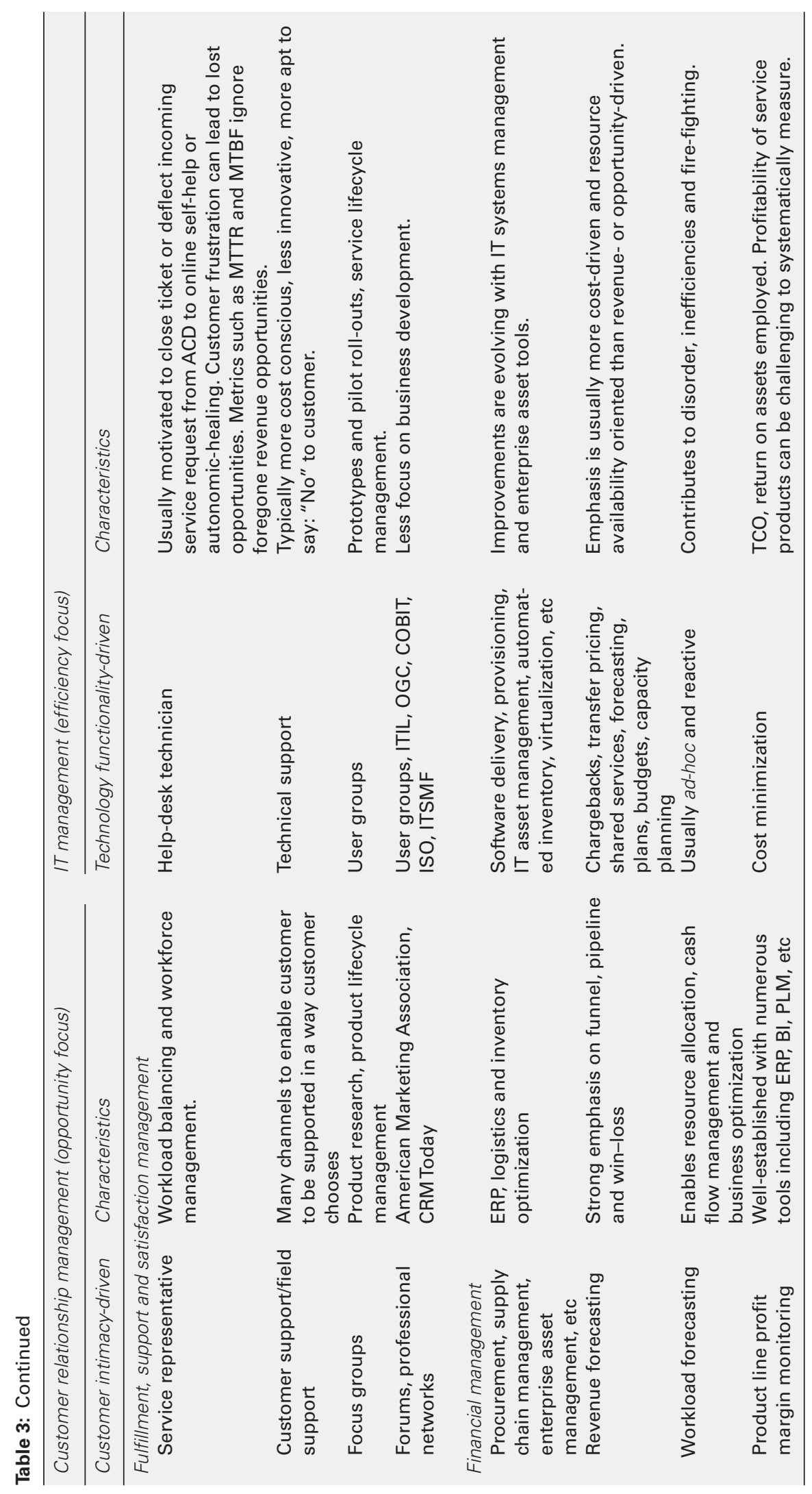




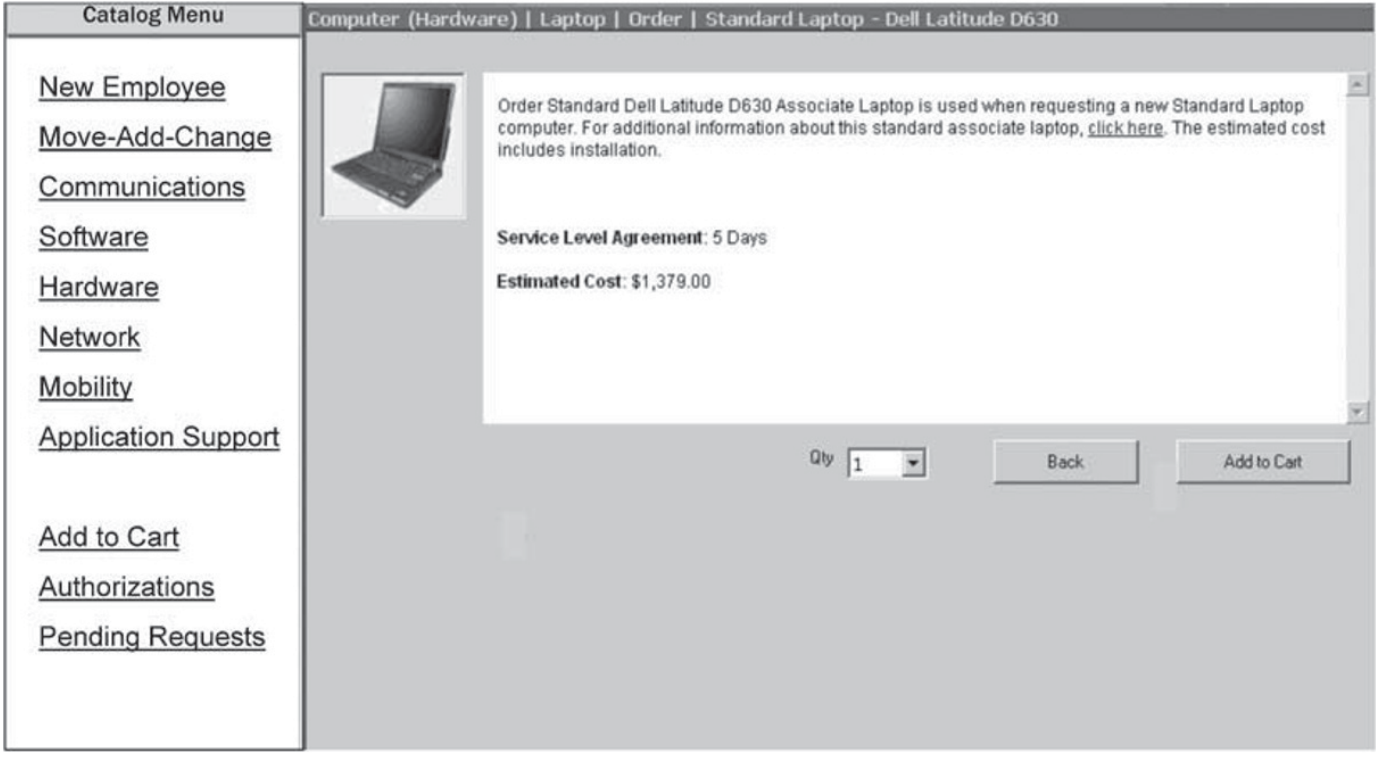

Figure 6: Catalogue example

more fluid these days. Organizational needs shift, and worker duties often need to shift. Despite some unionized encumbrances, what has evolved is a dynamic marketplace of projects and resource assignments. These assignments can feature internal and external competition, cosourcing and that mirrors the marketplace at large for revenue opportunities.

A service or product "goes to market" in increasingly varying teaming arrangements, compositions and formats. What can result is an e-Bay style clearing house as resources available align on-demand with work needing to be performed. If the market is robust, then the most qualified and most cost-effective resource is engaged and released with a minimum of friction, idle time or miscues (Table 2).

Due to the project/task marketplace that exists internally and externally, and due to several dynamics at work, IT professionals need to become better marketers. A range of prospective tools now exist for consideration. Table 3 shows similarities and differences of CRM compared to typical IT management in support of opportunity-driven service management practices.

\section{RECOMMENDATIONS}

In response to the question: "How can IT professionals be better marketers?”, the overall suggestions are to:
- be more opportunity driven and market aware;

- listen and record leads more systematically;

- refresh and renew continually solutions that the market will value;

- build morale and skills dynamically to earn current market-based rewards.

When managing the IT service lifecycle, it is beneficial to accommodate more of the customercentric opportunities and still preserve a framework for segregating duties, actor coordination and operational reliability. Indeed, it is not surprising to see more vendors as well as IT managers integrate more aspects of PSA, systems management, CRM and ITIL in their go-to-market IT offerings.

\section{Critically assess the current situation}

Determine if CRM, PPM, PSA and systems management solutions are at the proper levels of maturity within the organization. Do not attempt to accomplish too much, too early. An initial assessment of your current state and target state is a useful first step. A baseline inventory will tell you what is already in place, and identify potential for rationalizing, de-duping and streamlining, and the relative priorities.

2. Build a service catalogue and communicate a menu of offerings

Table 1 showed examples of offerings that can be communicated to consumers. The catalogue 
simplifies pricing, configuration, standard setting and change management. In conjunction with a change review board, obsolete offerings can be deleted, heterogeneity is controlled and support costs are reduced. The service pipeline leverages customer input to develop offerings for analysis, potential approval and charter. A service catalogue example is illustrated in Figure 6 to demonstrate a typical menu and functionality.

\section{Apply PSA}

Understand what PSA is, and why and where it could help. If PSA already exists, what potential exists to better integrate with service management and IT operations? Matching resources with requests can be simplified and useful techniques for better understanding users, consumers and suppliers can be continually improved.

4. Build and manage the task marketplace as a clearing house for resources available and work to be performed.

- The Opportunity Director is responsible for obtaining resources (from the pool of internal or external candidates).

- The Resource Coordinator administers and acts to fulfill requests from the staffing database (pool) to fulfill needs and deploy IT resources.

- The client representative, engagement leader, project manager(s), process consultants, product consultants and architect(s) are engaged to fulfill tasks and are released back to the resource pool upon completion.

Note that tools and techniques exist for managing tasks, opportunities, resumes, staff deployment, social networking including Linked-in, Facebook, online employee organizational directories, etc.

User-generated content and open source development (including homegrown wikipedia, social networking, etc.) is increasingly prevalent to enable dynamic updates by users, rather than rely solely on workers and system administrators to keep information up to date. Core IT staff can focus more on business relationship management, opportunity development, trends analysis, training delivery and process optimization when tasks are effectively managed. Connect to external suppliers where feasible or to economically supplement during demand peaks.

5. Leverage CRM principles and consider borrowing aspects of CRM functionality.

For example, various vendors offer rigorous CRM as well as service desk, asset management and configuration management solutions. Increasingly, internal IT customers can benefit from opportunity-oriented functionality. For example, computer-telephony integration and screen-pop scripts and knowledge bases that are effective in marketing call centers are also effective in IT service centers. Online chat, self-service, lead management and business intelligence techniques used for consumers can be adapted or extended for IT management.

\section{Adopt service process optimization and BPM methods.}

The ITIL framework is too valuable to ignore. The recent Version 3 updates emphasize the service lifecycle. Require all your vendors to use common standards and speak the language and terminology when addressing your problems, incidents and issues. Process standards that allow for lessons learned elsewhere about incident management, problem and change management, maximizing availability and overall process coordination need not only be authored inhouse. Avoid the "not-invented here" syndrome and embrace these published process standards wherever applicable.

\section{Update chargeback pricing mechanisms to enable} better SLAs and operating-level agreements.

Use more demand management techniques such as off-peak pricing to influence behavior to save on capacity, storage, energy consumption, reuse, etc. The market forces will lead to price reductions to clear orders, or raise prices when demand exceeds supply. As any good marketer knows, the selective bundling of services and solutions when negotiating prices with internal or external customers can drive better profit margins and inelasticity of demand.

8. Enhance the marketing prowess of IT professionals. Segment desired market spaces and target audiences. Identify, select and prioritize opportunities. "Can we win, do we want to 
win? How will it pay off? Is it scalable and repeatable?" Pick battles selectively in determining where resources are engaged and released.

Raise antennae for identifying new or changing needs. Log new opportunities that reflect user type and business circumstances in related or adjacent activities. In some organizations, this type of IT-business development role is known as "business relationship manager." This awareness is healthy and shows that some organizations realize business users often struggle in consuming IT services, and that these users have become less captive and are accessing more choices by various providers.

9. Enhance the marketing prowess and customer awareness of service center staff.

On a recent trip, I booked a low-fare flight with routing: New York-Baltimore-Chicago-Phoenix. Upon initially arriving at the airport, I noticed that a nonstop offering also existed for the same afternoon. I had to repeatedly explain to the ticketing agent my preference to skip the Baltimore and Chicago stops to arrive in Phoenix. The reservation system had generated the routing and the newly hired agent just could not put himself into the shoes of the customer to over-ride the system-generated routing, even though the system-generated offering represented a lower profit margin outcome and unhappy customer. Finally, an experienced agent intervened. Similarly, the mindset of service technicians responding to incidents and user requests is often rote and mechanical.

Faced with many possible scenarios, and sometimes limited training or experience, the diagnosis process can become mechanical, trialand-error, and can lose sight of the goals. Nevertheless, the brand is on display. The opportunity for the appropriate representative to build valuable customer relationships should not be ignored, in spite of pressures for costefficiency.

The service manager can maintain a pipeline of opportunities (and candidate projects) with prioritizations that consider origins of value and include objective metrics for ROI.
IT managers should more often prioritize resource deployments based on revenue, business urgency or other strategic considerations.

Handling requests, incidents and operations can be done with more than just a costminimization perspective. Instead, nurture select opportunities for customer touchpoints and satisfaction feedback. IT managers can become better marketers by measuring and rewarding workers for performing approved business development behaviors in addition to standard IT tasks. Capitalize on appropriate relationship building, promote customer-centric principles and apply relevant new service portfolio techniques.

\section{Adapt or be out-sourced}

Important trends are changing how to think about internal marketing and IT responsibilities. A shift is underway and IT professionals need to adapt.

Augment service desk operations, training and awareness. Adapt internal facing help-desk tools to incorporate inward-facing business development aspects. Which customers may need new services or additional functionality/ product? Who needs faster performance? Who needs new equipment faster? What barriers are encountered from the IT standpoint for performing the job better? Do not simply wait for occasional satisfaction surveys to trigger action.

When a deskside visit occurs, the technician can capture user information that will be relevant to fulfilling future needs. For example, adding new fields to the help-desk functionality may help capture, track and report new insights otherwise overlooked. With new automation tools such as automated inventory and selfhealing, the mundane deskside visits will decrease. Empower IT staff to gain customer awareness and provide input to developing new service concepts.

The best workers are motivated to pre-empt any likelihood of out-sourcing. Whether it is in the form of SaaS, ASP or shifting application development and data center work to an IBM or Cap Gemini to focus on core strengths, an organization's approach to out-sourcing can ebb and flow depending on shifting priorities, market opportunities and strategies. Naturally, 
being proactive enables higher value-add work to be instigated and retained by the team members. With a focus that is less task oriented, more analytical and more business development oriented, the team members can influence their destiny and reduce the likelihood of stagnating in yesterday's outmoded approaches.

\section{Design rewards that reinforce desired behavior.} Interviews at a major corporation recently revealed the following conflict: "People here don't use self-service for automated password resets. We don't remind them about it, because we're compensated on quantity of incident tickets we process." The incentives and rewards systems must be regularly reviewed to ensure that IT and business objectives are aligned.

Rewards systems must be straightforward enough for employees to understand the goal congruence. Eliminate incentives that discourage good behavior or encourage bad behavior. Workers have job descriptions with defined responsibilities that encourage adherence to foster coordination and efficiency. But regularly look at role profiles and update job descriptions regularly. As more roles such as Business Relationship Manager are approved in an organization, the ability to apply a business-development and marketing mindset for IT managers will improve.

\section{CONCLUSION}

How CIOs spend their time

\begin{tabular}{ll}
\hline $23 \%$ & Relationship management with business \\
$16 \%$ & Strategy \\
$13 \%$ & Relationship management with IT \\
$9 \%$ & IT governance \\
$8 \%$ & Operations \\
$8 \%$ & Architecture \\
$8 \%$ & HR \\
$7 \%$ & Non-IT \\
$6 \%$ & Software development
\end{tabular}

Data: Society for information management survey of $130 \mathrm{ClOs}$ and senior IT executives. Information-Week.

In a survey of $130 \mathrm{CIOs}$ and senior IT executives, 23 per cent of their time was reported as spent on relationship management with business and 8 per cent on operations.

IT managers and staff reporting up to CIOs are often burdened by operational, architectural and managerial duties. Hence, it can be challenging to additionally accept marketing, innovation and pipeline management responsibilities. Nevertheless, opportunities for business development and retaining customer loyalty should be embraced.

Opportunity-driven service management brings together new and established methods. Go-to-market results are more timely, more efficient and less risky. The service pipeline, service catalogue, PSA and CRM techniques will help IT professionals seize more opportunities with greater market impact.

\section{GLOSSARY}

\begin{tabular}{|c|c|}
\hline Term & Explanation \\
\hline Change & $\begin{array}{l}\text { A deviation from status quo that may need to be managed depending on the nature of } \\
\text { the proposed change. Risk mitigation techniques can include rigorous policies, change } \\
\text { control procedures or use of a Change Advisory Board. }\end{array}$ \\
\hline $\mathrm{Cl}$ & $\begin{array}{l}\text { Configuration items are characteristics recorded in a database (CCMDB) to capture } \\
\text { attributes and relationships such as hardware model, serial number, software version, } \\
\text { documentation manual, work product, etc. }\end{array}$ \\
\hline CMS & $\begin{array}{l}\text { Configuration management system manages } \mathrm{Cls} \text { and may contain multiple } \\
\text { configuration Mgmt databases. }\end{array}$ \\
\hline Contract & Negotiated agreement in writing with obligations for provider and consumer. \\
\hline CRM & $\begin{array}{l}\text { Customer relationship management offers solutions and techniques for managing } \\
\text { revenue opportunities, contacts, organizations and leads evolved in the late 1990s. } \\
\text { Since then, firms such as Siebel, Oracle, Epiphany and Unica have implemented } \\
\text { large-scale deployments. }\end{array}$ \\
\hline CTI & $\begin{array}{l}\text { Computer Telephony Integration enables more seamless data and knowledge sharing } \\
\text { among devices and interfaces. }\end{array}$ \\
\hline
\end{tabular}




\begin{tabular}{|c|c|}
\hline Term & Explanation \\
\hline ERP & $\begin{array}{l}\text { Enterprise resource planning integrates several components of manufacturing, pricing, } \\
\text { fulfillment, inventory management, distribution, reporting, etc. }\end{array}$ \\
\hline Incident & An event of non-routine significance needing attention from IT. \\
\hline ITIL v3 & $\begin{array}{l}\text { IT Infrastructure Library Version } 3 \text { is published by OGC in the United Kingdom; these process } \\
\text { optimization books describe the service cycle. The components include service strategy, } \\
\text { service design, service transition, service operation and continual service improvement. }\end{array}$ \\
\hline MTBF & $\begin{array}{l}\text { Mean time between fixes measures reliability, outages and service management } \\
\text { effectiveness. }\end{array}$ \\
\hline MTTR & Mean time to resolution measures downtime and service management effectiveness \\
\hline OGC & Office of Government Commerce, United Kingdom. \\
\hline OLA & $\begin{array}{l}\text { Operational-level agreement can exist between IT service provider and a different } \\
\text { department of the same organization that assists with the provision of services } \\
\text { (e.g. Facilities team maintains air conditioning, or network support team that supports } \\
\text { the network service.). }\end{array}$ \\
\hline Opportunity & $\begin{array}{l}\text { Used by sales, marketing or fulfillment workers to represent the chance to generate } \\
\text { revenue by providing a proposed product or service. }\end{array}$ \\
\hline Pipeline & Service products conceptualized and under development pending approval and charter. \\
\hline PLM & $\begin{array}{l}\text { Product lifecycle management solutions help companies improve product development, prod- } \\
\text { uct introduction processes and use of product-related information across lines of business. }\end{array}$ \\
\hline PSA & $\begin{array}{l}\text { Professional services automation manages delivery of client projects, and the } \\
\text { resources required, such as skilled people and assets. Functions may include project } \\
\text { management, documentation, time records, billing, reporting, etc. }\end{array}$ \\
\hline Request & $\begin{array}{l}\text { A user or customer takes the initiative to request an action or task be addressed by the } \\
\text { support provider. }\end{array}$ \\
\hline SCM & $\begin{array}{l}\text { Supply chain management solutions help companies improve supplier relations and } \\
\text { supply logistics. }\end{array}$ \\
\hline Service catalogue & $\begin{array}{l}\text { A catalogue of services and capabilities offered by the provider organization to the } \\
\text { consumer organization. The catalogue is the section of the service portfolio viewable } \\
\text { by customers. The products that are retired or under development are generally not } \\
\text { displayed in the customer view of the catalogue. }\end{array}$ \\
\hline Service portfolio & The service portfolio is comprised of the service pipeline and the service portfolio \\
\hline SKMS & Service knowledge management system. \\
\hline SLA & $\begin{array}{l}\text { Service-level agreement negotiated between provider and business consumer. An } \\
\text { understanding about priorities, warranty and level of service. }\end{array}$ \\
\hline $\begin{array}{l}\text { Systems } \\
\text { management }\end{array}$ & $\begin{array}{l}\text { The evolving set of solutions such as automated inventory, software delivery, change } \\
\text { and configuration management systems, asset management, etc. The vision is for a suite } \\
\text { analogous to ERP that will provide a } \mathrm{CIO} \text { dashboard with business intelligence capabilities. }\end{array}$ \\
\hline $\mathrm{T} \& \mathrm{Cs}$ & Terms and conditions of an agreement set out the rights and obligations of the parties \\
\hline UC & $\begin{array}{l}\text { Underpinning contracts negotiated between external supplier and organization } \\
\text { provider of delivery services. }\end{array}$ \\
\hline
\end{tabular}

\section{Further Reading}

Evans, B. (2007) 'The inexorable rise of the new CIO', Information Week, 19 November 2007.

Soat, J. (2007) 'IBM's CIO: A conversation with Mark Hennessy', Information Week, 19 December 2007.

ITIL. (2007) 'Information technology infrastructure library books', Office of Government Commerce, May 2007. 